NASA/TM-2000-210238

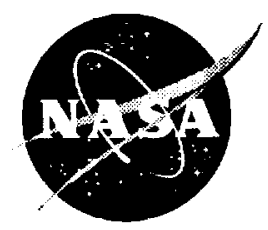

\title{
Thermal Conductivity of EB-PVD Thermal Barrier Coatings Evaluated by a Steady-State Laser Heat Flux Technique
}

Dongming Zhu

Ohio Aerospace Institute, Cleveland, Ohio

Robert A. Miller

Glenn Research Center, Cleveland, Ohio

Ben A. Nagaraj and Robert W. Bruce

General Electric Aircraft Engines, Cincinnati, Ohio 
The NASA STI Program Office . . . in Profile

Since its founding, NASA has been dedicated to the advancement of aeronautics and space science. The NASA Scientific and Technical Information (STI) Program Office plays a key part in helping NASA maintain this important role.

The NASA STI Program Office is operated by Langley Research Center, the Lead Center for NASA's scientific and technical information. The NASA STI Program Office provides access to the NASA STI Database, the largest collection of aeronautical and space science STI in the world. The Program Office is also NASA's institutional mechanism for disseminating the results of its research and development activities. These results are published by NASA in the NASA STI Report Series, which includes the following report types:

- TECHNICAL PUBLICATION. Reports of completed research or a major significant phase of research that present the results of NASA programs and include extensive data or theoretical analysis. Includes compilations of significant scientific and technical data and information deemed to be of continuing reference value. NASA's counterpart of peerreviewed formal professional papers but has less stringent limitations on manuscript length and extent of graphic presentations.

- TECHNICAL MEMORANDUM. Scientific and technical findings that are preliminary or of specialized interest, e.g., quick release reports, working papers, and bibliographies that contain minimal annotation. Does not contain extensive analysis.

- CONTRACTOR REPORT. Scientific and technical findings by NASA-sponsored contractors and grantees.
- CONFERENCE PUBLICATION. Collected papers from scientific and technical conferences, symposia, seminars, or other meetings sponsored or cosponsored by NASA.

- SPECIAL PUBLICATION. Scientific, technical, or historical information from NASA programs, projects, and missions, often concerned with subjects having substantial public interest.

- TECHNICAL TRANSLATION. Englishlanguage translations of foreign scientific and technical material pertinent to NASA's mission.

Specialized services that complement the STI Program Office's diverse offerings include creating custom thesauri, building customized data bases, organizing and publishing research results ... even providing videos.

For more information about the NASA STI Program Office, see the following:

- Access the NASA STI Program Home Page at http://www.sti.nasa.gov

- E-mail your question via the Internet to help@sti.nasa.gov

- Fax your question to the NASA Access Help Desk at (301) 621-0134

- Telephone the NASA Access Help Desk at (301) 621-0390

- Write to: NASA Access Help Desk NASA Center for AeroSpace Information 7121 Standard Drive Hanover, MD 21076 
NASA/TM-2000-210238

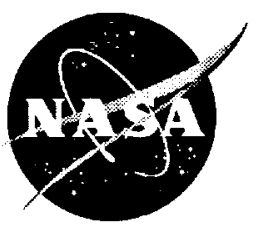

\section{Thermal Conductivity of EB-PVD Thermal Barrier Coatings Evaluated by a Steady-State Laser Heat Flux Technique}

Dongming Zhu

Ohio Aerospace Institute, Cleveland, Ohio

Robert A. Miller

Glenn Research Center, Cleveland, Ohio

Ben A. Nagaraj and Robert W. Bruce

General Electric Aircraft Engines, Cincinnati, Ohio

Prepared for the

International Conference on Metallurgical Coatings and Thin Films sponsored by the American Vacuum Society

San Diego, California, April 10-14, 2000

National Aeronautics and Space Administration

Glenn Research Center 
Available from

NASA Center for Aerospace Information

7121 Standard Drive

Hanover, MD 21076

Price Code: A03
National Technical Information Service 5285 Port Royal Road Springfield, VA 22100 Price Code: A03 


\title{
THERMAL CONDUCTIVITY OF EB-PVD THERMAL BARRIER COATINGS EVALUATED BY A STEADY-STATE LASER HEAT FLUX TECHNIQUE
}

\author{
Dongming Zhu and Robert A. Miller \\ National Aeronautics and Space Administration \\ Glenn Research Center \\ Cleveland, Ohio 44135 \\ Ben A. Nagaraj and Robert W. Bruce \\ General Electric Aircraft Engines \\ Cincinnati, Ohio 45215
}

\begin{abstract}
The thermal conductivity of electron beam-physical vapor deposited (EB-PVD) $\mathrm{ZrO}_{2}-8 \mathrm{wt} \% \mathrm{Y}_{2} \mathrm{O}_{3}$ thermal barrier coatings was determined by a steady-state heat flux laser technique. Thermal conductivity change kinetics of the EB-PVD ceramic coatings were also obtained in real time, at high temperatures, under the laser high heat flux, long-term test conditions. The thermal conductivity increase due to micro-pore sintering and the decrease due to coating micro-delaminations in the EB-PVD coatings were evaluated for grooved and non-grooved EB-PVD coating systems under isothermal and thermal cycling conditions. The coating failure modes under the high heat flux test conditions were also investigated. The test technique provides a viable means for obtaining coating thermal conductivity data for use in design, development, and life prediction for engine applications.
\end{abstract}

\section{INTRODUCTION}

Ceramic thermal barrier coatings (TBCs) have received increasing attention for advanced gas turbine engine applications because of their ability to effectively protect the

Paper presented at The International Conference on Metallurgical Coatings and Thin Films, San Diego, California, April 10-14, 2000. 
cooled, metal components in engine hot sections. Since coating thermal conductivity directly impacts the engine performance and reliability, low thermal conductivity becomes one of the most critical requirements for thermal barrier coatings. The current $\mathrm{ZrO}_{2}-8 \mathrm{wt} \% \mathrm{Y}_{2} \mathrm{O}_{3}$ coating material has a relatively low intrinsic thermal conductivity (about $2.5 \mathrm{~W} / \mathrm{m}-\mathrm{K}$ ). Further conductivity reductions have largely been achieved by incorporating micropores and microcracks within the ceramic coating systems. However, the thermal conductivity reduction provided by the microporosity may not persist because the ceramic coating can sinter at high temperatures [1-6]. Therefore, not only the coating initial thermal conductivity but also the changes in coating conductivity during service are of great importance for the development of advanced thermal barrier coatings.

In order to evaluate the change kinetics of the coating thermal conductivity that are necessary for coating design and life prediction, a steady-state laser heat flux technique has been developed $[5,6]$. This technique has previously been used to determination of the thermal conductivity evolution of the plasma-sprayed $\mathrm{ZrO}_{2}$ $8 \mathrm{wt} \% \mathrm{Y}_{2} \mathrm{O}_{3}$ thermal barrier coating systems under high heat flux conditions. The thermal conductivity data have successfully provided insight into the sintering, creep, and failure modes of the coating systems [7].

In this paper, the laser steady-state heat flux technique is used to investigate the thermal conductivity of EB-PVD thermal barrier coatings. Thermal conductivity change kinetics of the EB-PVD ceramic coatings were obtained, under both long-term isothermal and cyclic conditions at high temperatures, for EB-PVD coating systems having both grooved and non-grooved bond coats. The thermal conductivity changes with time were evaluated in terms of two competing processes: that is, the conductivity increases due to micro-pore sintering and the conductivity decreases due to coating micro-delaminations. The failure mechanisms were also investigated and compared for the EB-PVD coating systems with both bond coat surface grooved and non-grooved specimens under the laser high heat flux testing conditions.

\section{Experimental Materials and Methods}

Materials

EB-PVD $\mathrm{ZrO}_{2}-8 \mathrm{wt} \% \mathrm{Y}_{2} \mathrm{O}_{3}$ coated specimens were prepared by General Electric Aircraft Engines Company, Cincinnati, Ohio. In this thermal conductivity study, 
25.4-mm-diameter and 3.2-mm-thick René N5 circular disk specimens were used as substrates. The substrates were first coated with a $0.12 \mathrm{~mm}$-thick $\mathrm{PtAl}$ bond coat. Two types of bond coat configurations were used. One was the regular flat surface bond coat system, and the other was laser-surface-grooved bond coats with a square-grid-type groove arrangement. The bond coat grooves are intended to enhance the ceramic top-coat durability. The grooves were about $20 \mu \mathrm{m}$ in width and $200 \mu \mathrm{m}$ in spacing. Finally, the ceramic coatings with various thicknesses of $0.13,0.25$ and $1.0 \mathrm{~mm}$ were deposited onto the substrate-bond coat systems using the EB-PVD technique.

\section{Thermal Conductivity Testing}

Thermal conductivity testing was performed on the EB-PVD coating systems using a $3.0 \mathrm{~kW}$ laser high-heat flux rig. The test rig systems and the general approaches have been described elsewhere [5,8]. A schematic diagram of the laser heat flux rig is illustrated in Figure 1. In the laser thermal conductivity test, the specimen surface heating was provided by the laser beam, and backside air cooling was used to maintain the desired specimen temperatures. A 12.5-mm-thick aluminum plate with a $23.9 \mathrm{~mm}$ diameter center hole opening served as an aperture to prevent edge- or side-heating of the specimen. A uniform laser power distribution was achieved over a $23.9 \mathrm{~mm}$ diameter aperture region of the specimen by using an integrating $\mathrm{ZnSe}$ lens combined with the specimen rotation. Platinum wire flat coils (wire diameter $0.38 \mathrm{~mm}$ ) were used to form thin air gaps between the top aluminum aperture plate and stainless-steel back plate to minimize the specimen heat losses through the fixture.

The thermal conductivity of the ceramic coating was determined from the passthrough heat flux and the measured temperature gradients through the ceramic coating system under the steady-state laser heating conditions using a one-dimensional (one-D) heat transfer model $[5,8]$. The laser delivered heat flux was calibrated using a $127 \mu \mathrm{m}$ thick plasma-sprayed $\mathrm{ZrO}_{2}-\mathrm{Y}_{2} \mathrm{O}_{3}$ on a CMSX-4 superalloy substrate of known conductivity. The actual pass-through heat flux was obtained by subtracting the laser reflection loss (measured by a $10 \mu \mathrm{m}$ reflectometer) and the calculated radiation heat loss (total emissivity was taken as 0.50 ) at the ceramic coating surface. The pass-through heat 
flux was also verified with an internal heat flux gauge that was incorporated with selected metal substrates via an embedded miniature thermocouple.

Because of the well-calibrated heat flux and the known metal conductivity, only the ceramic surface and the metal back surface temperatures were necessary for determining the ceramic coating conductivity. During the test, the ceramic surface temperature was measured by an $8 \mu \mathrm{m}$ infrared pyrometer. The back surface of the metal substrate was measured by both a two-color infrared pyrometer and a calibrated $8 \mu \mathrm{m}$ infrared pyrometer. The ceramic/metal interface temperature was obtained using the known thermal conductivity values of the René N5 metal substrate, and thus, the temperature difference across the ceramic were readily derived. Overall coating thermal conductivity as functions of coating thickness, temperature, and testing time was determined from the heat fluxes and corresponding temperature gradients across the ceramic coating.

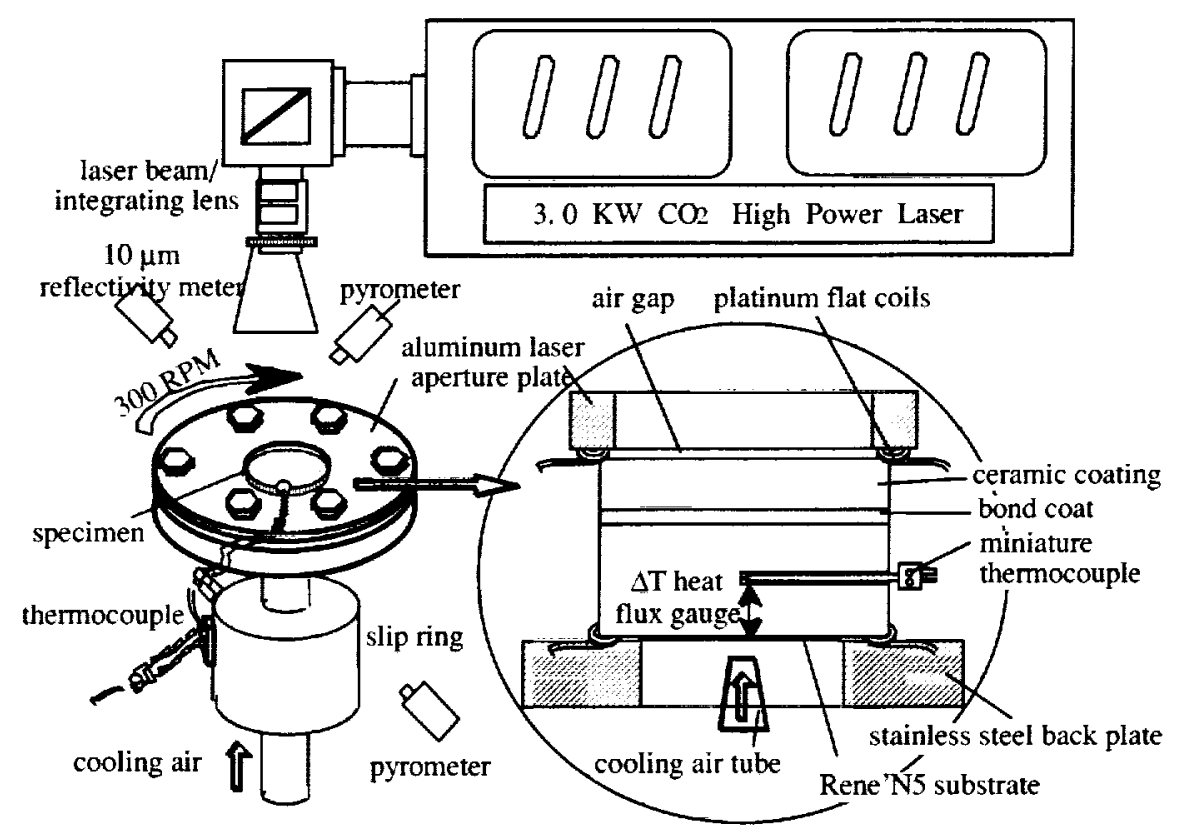

Fig. 1 Laser high heat flux rig for measuring thermal conductivity of thermal barrier coatings. During the test, the ceramic surface and the metal back surface temperatures are measured by infrared pyrometers. The metal substrate midpoint temperature can be monitored with an embedded miniature type-K thermocouple. The interfacial temperatures, and the actual heat flux passing through the thermal barrier coating system, are therefore determined under the steady-state laser heating conditions by a one-dimensional (one-D) heat transfer model $[5,8]$. 
It should be mentioned that the errors in determining the interface temperature increase as the coating conductance (conductivity/thickness) increases relative to the substrate conductance. A thin EB-PVD TBC tested at high heat flux may be especially unfavorable. Care must be taken to accurately calculate the temperature gradients across the metal substrate. Therefore, the use of a single value for the substrate conductivity may not be sufficiently accurate due to its strong temperature dependence, as illustrated in the curve labelled $k_{\text {metal }}$-actual in Figure 2 . In this study, a more accurate approach was employed to calculate the temperature difference across the ceramic coating, by dividing the substrate into sublayers each having temperature dependent conductivity

$$
\nabla T_{\text {ceramic }}=T_{\text {ceramic-surafce }}-T_{\text {metal-back }}-\frac{q_{\text {thru }} \cdot t_{\text {bond }}}{k_{\text {bond }}(T)}-\sum_{i} \frac{q_{\text {thru }} \cdot t_{\text {metal }}^{i}}{k_{\text {metal }}^{i}(T)}
$$

where the $\nabla T_{\text {ceramic }}$ is the temperature difference across the ceramic coating, $T_{\text {ceranic-surafice }}$ and $T_{\text {metal-back }}$ are measured ceramic surface and metal back surface temperatures, $q_{t h r u}$ is pass-through heat flux, $t_{\text {bond }}, t_{\text {metal }}^{i}$, and $k_{\text {bond }}(T)$ and $k_{\text {meral }}^{i}(T)$ are the thicknesses and thermal conductivity of the bond coat and the ith layer substrate, respectively. Figure 2 illustrates the potential range of calculated interface temperatures based on the use of a lower-bound-vs. upper-bound- vs. temperature dependent-metal thermal conductivities. 


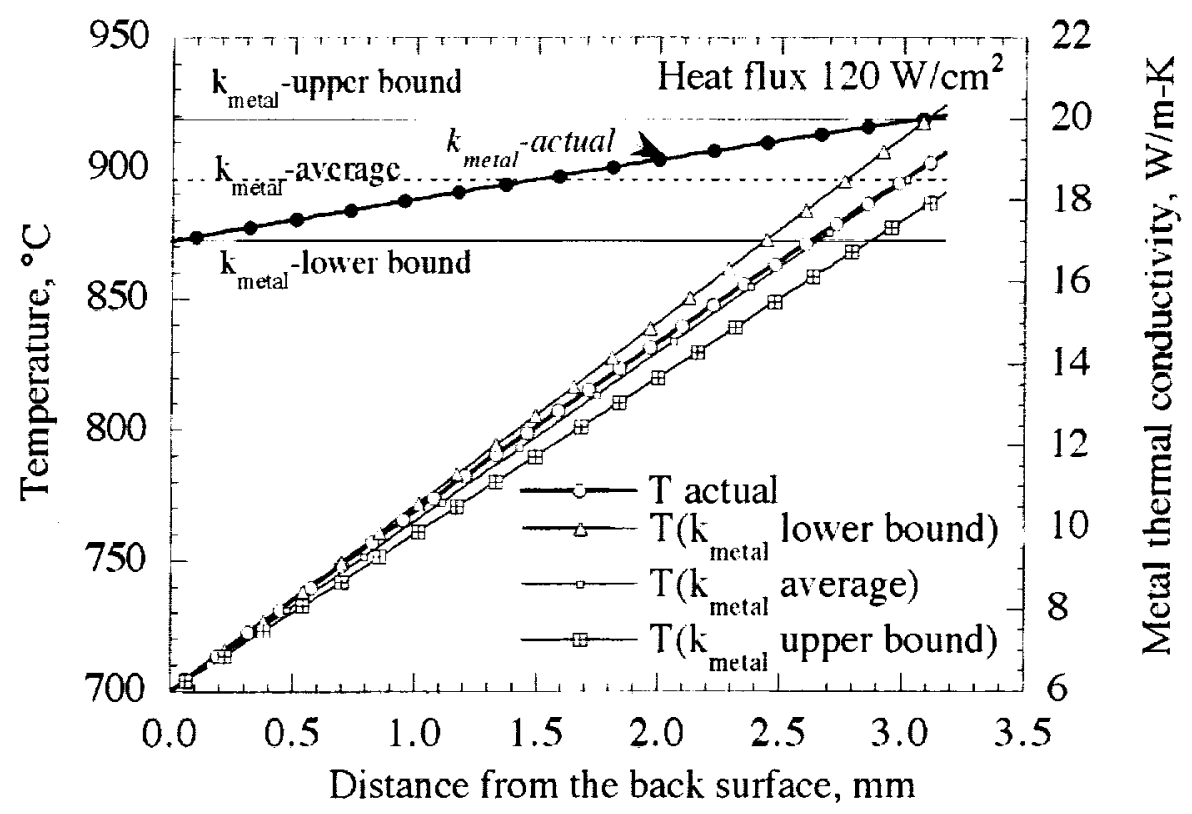

Fig. 2 The calculated temperature distributions in a René N5 superalloy specimen. From the measured metal back surface temperature of $700^{\circ} \mathrm{C}$, the ceramic /metal interface temperature can be incorrectly extrapolated depending on which conductivity values are used. The curvature in the metal temperature distribution is also observed due to the metal conductivity increase with temperature.

\section{EXPERIMENTAL RESULTS AND DISCUSSION}

\section{Thermal Conductivity Change Kinetics of EB-PVD Coatings}

Thermal conductivity change kinetics of EB-PVD coatings were determined on the laser test rig under isothermal and $2 \mathrm{hr}$-cyclic conditions. The test conditions are shown in Table 1. A constant heat flux was used for each test, and the heat flux was chosen according to the specimen ceramic coating thickness.

Figure 3 shows thermal conductivity change kinetics of the EB-PVD coatings determined from the laser test rig under the isothermal and $2 \mathrm{hr}$-cyclic conditions. It can be seen under all test conditions, that the coating conductivity generally tended to 
increase with time. Under the isothermal test conditions, the EB-PVD coatings usually show a monotonic conductivity increase, as shown in Figure 3 (a) for the $0.25-\mathrm{mm}$ and $1.0-\mathrm{mm}$ thick coating cases. Under the 2 hour cyclic test conditions, the EB-PVD coatings showed some thermal conductivity variations during the thermal cycling, as illustrated in Figure 3 (b), indicating the coating cracking occurred during the cycling. For the 0.13-mm thick, non-grooved EB-PVD coating, the conductivity fluctuations were not significant during the normal testing period (which the coating failure had not occurred). However, for the $0.13-\mathrm{mm}$ thick, grooved EB-PVD coating, significant conductivity variations were noticed during the entire test period, suggesting more severe micorscale delamination cracking for the grooved specimen as compared for the nongrooved specimen. Another 0.13-mm thick, grooved EB-PVD specimen was 2 hour cyclic tested up to 200 hot hours. An overall conductivity increase and large conductivity fluctuations were also observed for this specimen during the long-term testing, as shown in Figure 4.

Because of the large differences in the tested coating thickness, the thermal conductivity of the EB-PVD coatings were actually tested at different ranges of temperatures. Temperature dependence of the rate of conductivity increase may be derived from the test results. Figure 5 shows the steady-state conductivity rate increase as a function of the reciprocal average testing temperature. The results show that the EBPVD coating conductivity increase is a thermally activated process.

Table 1 Test conditions for thermal conductivity change kinetics of EB-PVD coatings

\begin{tabular}{|l|c|c|c|c|}
\hline \multicolumn{1}{|c|}{ Specimen } & Test type & $\begin{array}{c}\text { Passing-through-heat } \\
\text { flux }\left(\mathrm{W} / \mathrm{cm}^{2}\right)\end{array}$ & $\begin{array}{c}\text { Tsurface } \\
\left({ }^{\circ} \mathrm{C}\right)\end{array}$ & $\begin{array}{c}\text { Tinterface } \\
\left({ }^{\circ} \mathrm{C}\right)\end{array}$ \\
\hline $\begin{array}{l}0.13 \mathrm{~mm} \text { grooved EB- } \\
\text { PVD coating }\end{array}$ & 2-hr cyclic & 220 & 1280 & 1095 \\
\hline $\begin{array}{l}0.13 \mathrm{~mm} \text { non-grooved } \\
\text { EB-PVD coating }\end{array}$ & 2-hr cyclic & 220 & 1280 & 1095 \\
\hline $\begin{array}{l}0.25 \mathrm{~mm} \text { non-grooved } \\
\text { EB-PVD coating }\end{array}$ & isothermal & 143 & 1250 & 1020 \\
\hline $\begin{array}{l}1.0 \mathrm{~mm} \text { non-grooved } \\
\text { EB-PVD coating }\end{array}$ & isothermal & 69 & 1350 & 860 \\
\hline
\end{tabular}




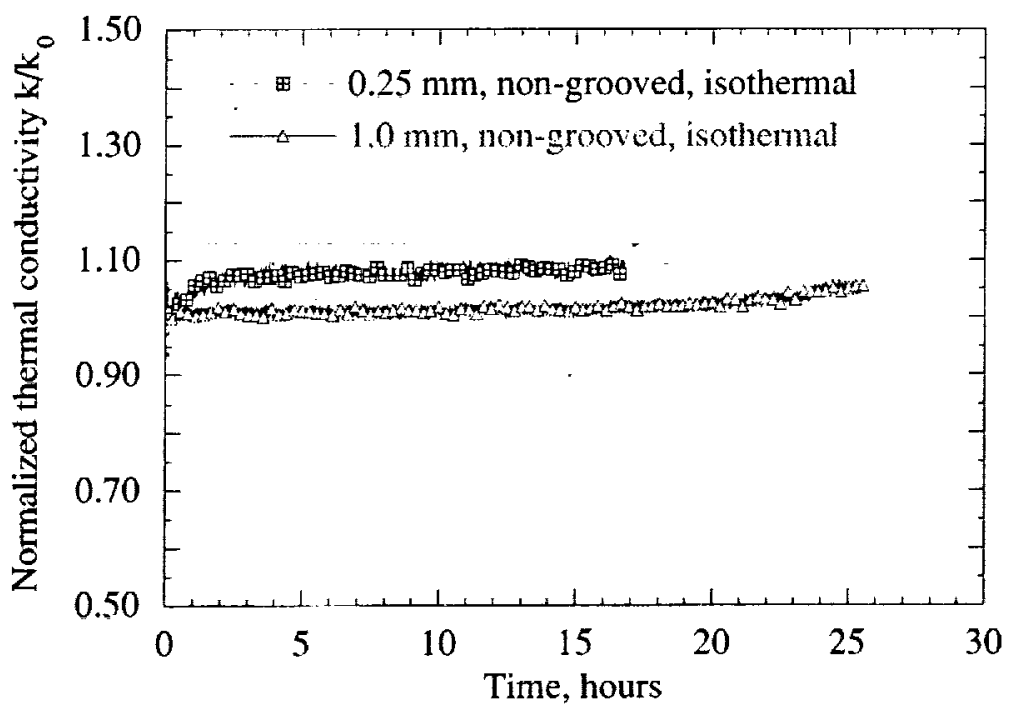

(a)

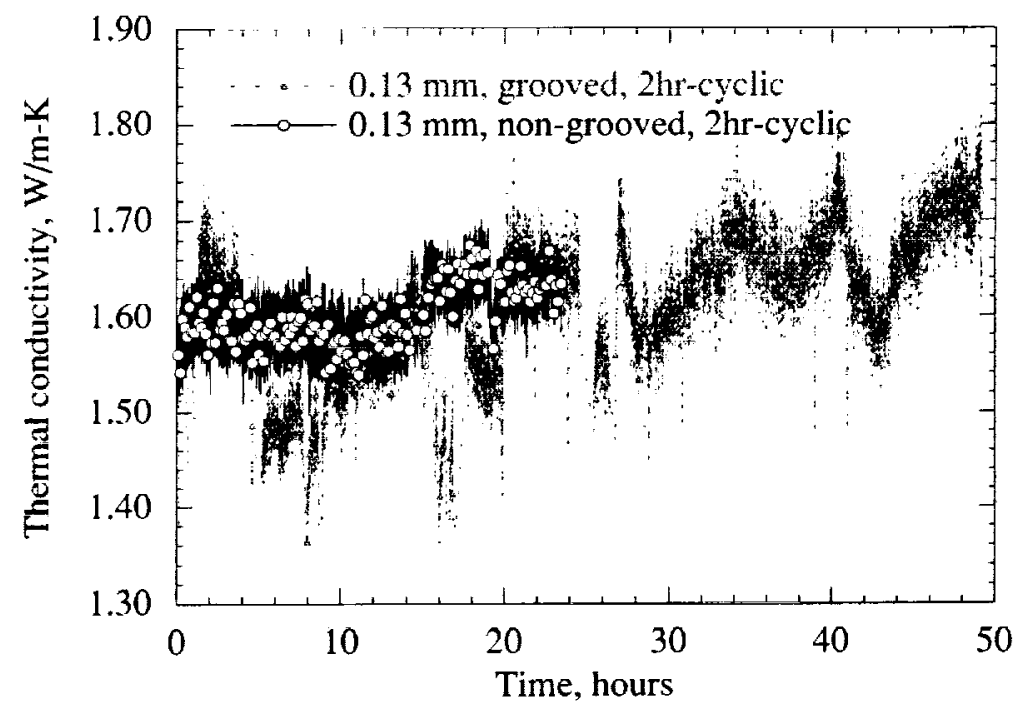

(b)

Fig. 3 Thermal conductivity change kinetics of the EB-PVD coatings determined using the steady-state laser heat flux technique. (a) Thermal conductivity of $0.25 \mathrm{~mm}$ and $1.0 \mathrm{~mm}$ coatings under laser isothermal test condition. (b) Thermal conductivity of $0.13 \mathrm{~mm}$ coatings with grooved and non-grooved bond coats under laser $2 \mathrm{hr}$ cyclic test conditions. 


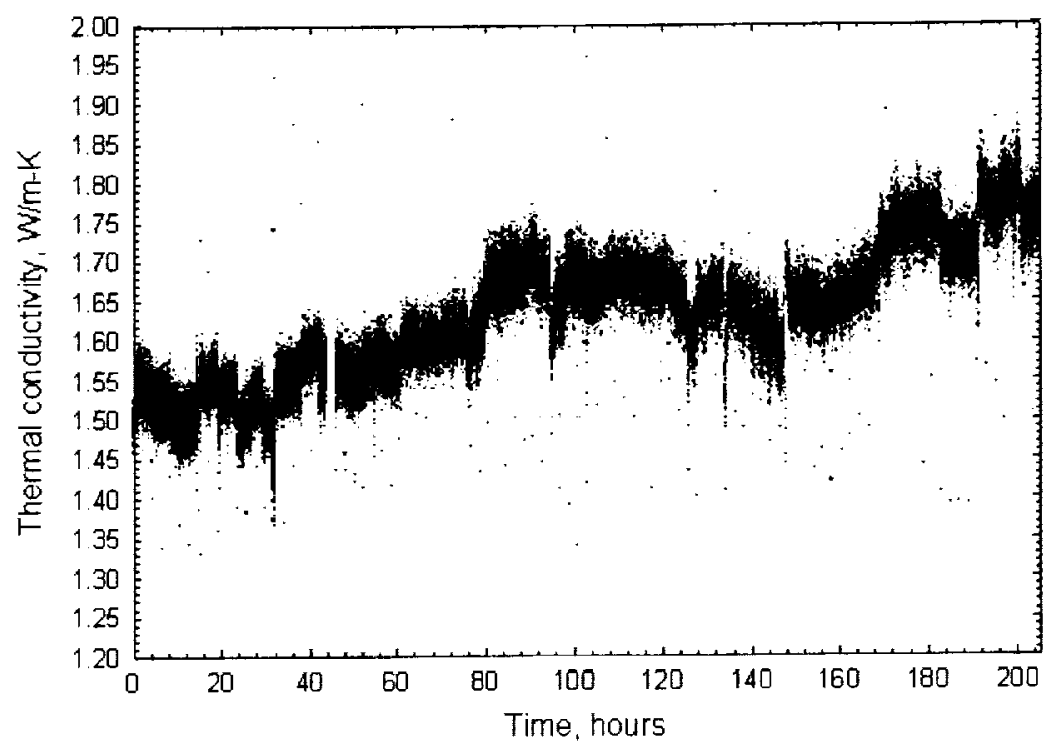

Fig. 4 The overall conductivity increase and large conductivity fluctuation for a 0.13 $\mathrm{mm}$ thick EB-PVD coating during the 2-hr cyclic, total 200 hot hr test (the initial conductivity value is normalized to a typical EB-PVD coating conductivity value of $1.5 \mathrm{~W} / \mathrm{m}-\mathrm{K})$.

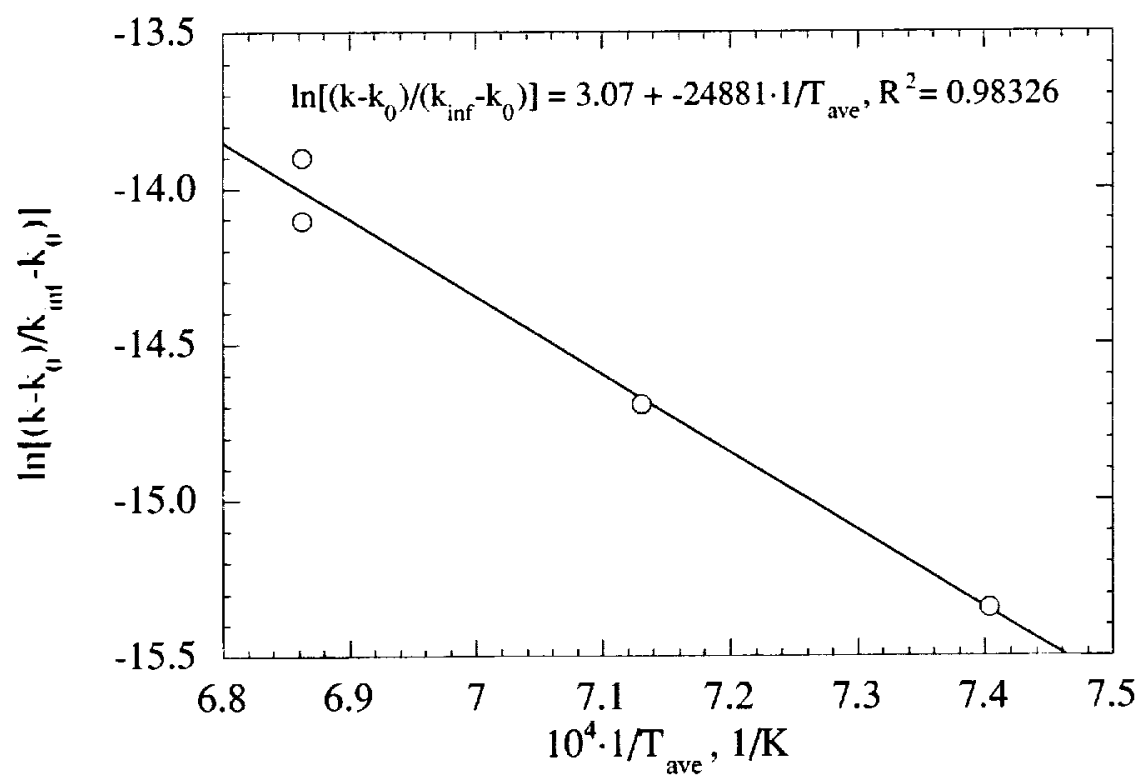

Fig. 5 The rate of the steady-state conductivity increase as a function of the reciprocal average testing temperature. 
Sintering of EB-PVD coatings

Sintering and corresponding microstructural changes of EB-PVD coatings are unique under high heat flux conditions. It is known that for the EB-PVD thermal barrier coatings, high porosity is present in the in-plane directions between the columnar grains. Sintering of the EB-PVD coatings was observed as "welding" of the loose individual columnar grains, thus generating coating through-thickness cracks in order to make up the deficit strains. Figure 6 shows a surface morphology of sintered columnar grains and a resulting surface crack in an EB-PVD coating.

Under the laser high heat flux testing, wedge-shape through-thickness cracks are often observed because the sintering strains are usually higher near the coating surface than near the interface, corresponding to the temperature gradient across the coating. The crack opening displacements can be correlated to the in-plane sintering and creep strains of EB-PVD coatings using the laser sintering-creep approach [9]. Figure 7 shows the coating surface sintering strains derived from the surface crack displacements for the grooved EB-PVD coating specimens as a function of time. The results show that the coating sintering strains increase with time. The significant sintering of inter-columnar pores has also been observed in the $1.00 \mathrm{~mm}$ thick EB-PVD coatings especially near the surface region after the laser testing, as shown in the Figure 8. 


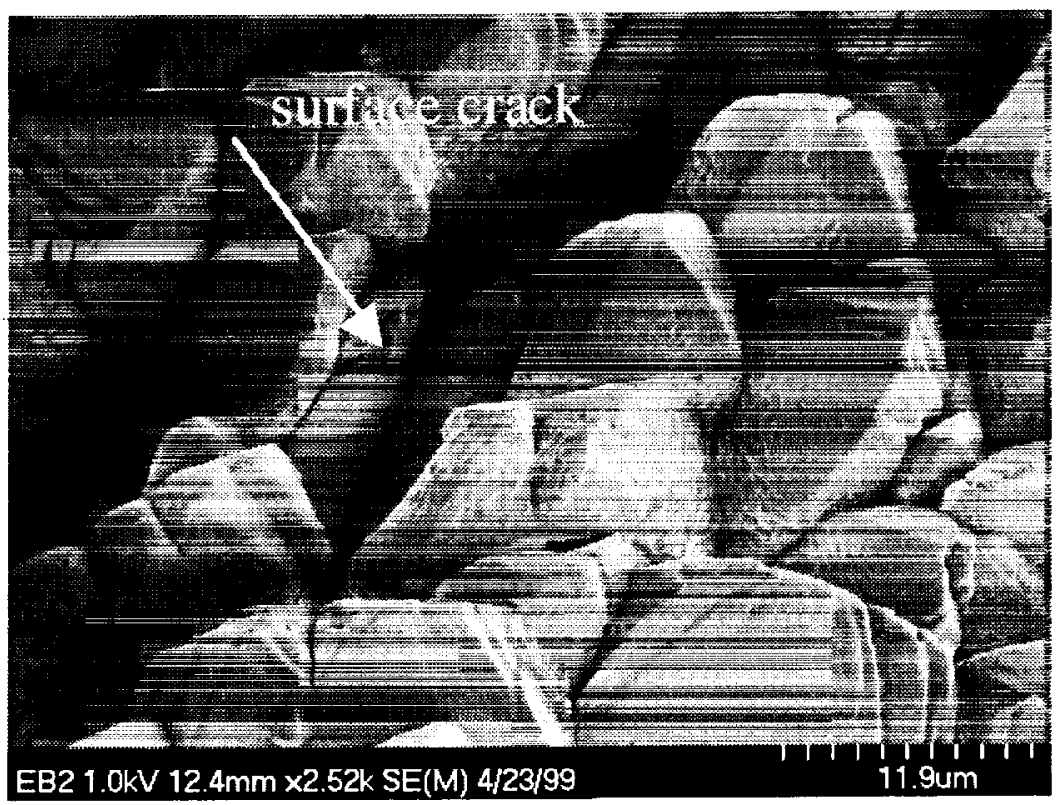

Fig. 6 Micrograph of the coating surface morphology showing sintered columnar grains and a resulting surface crack in an EB-PVD coating.

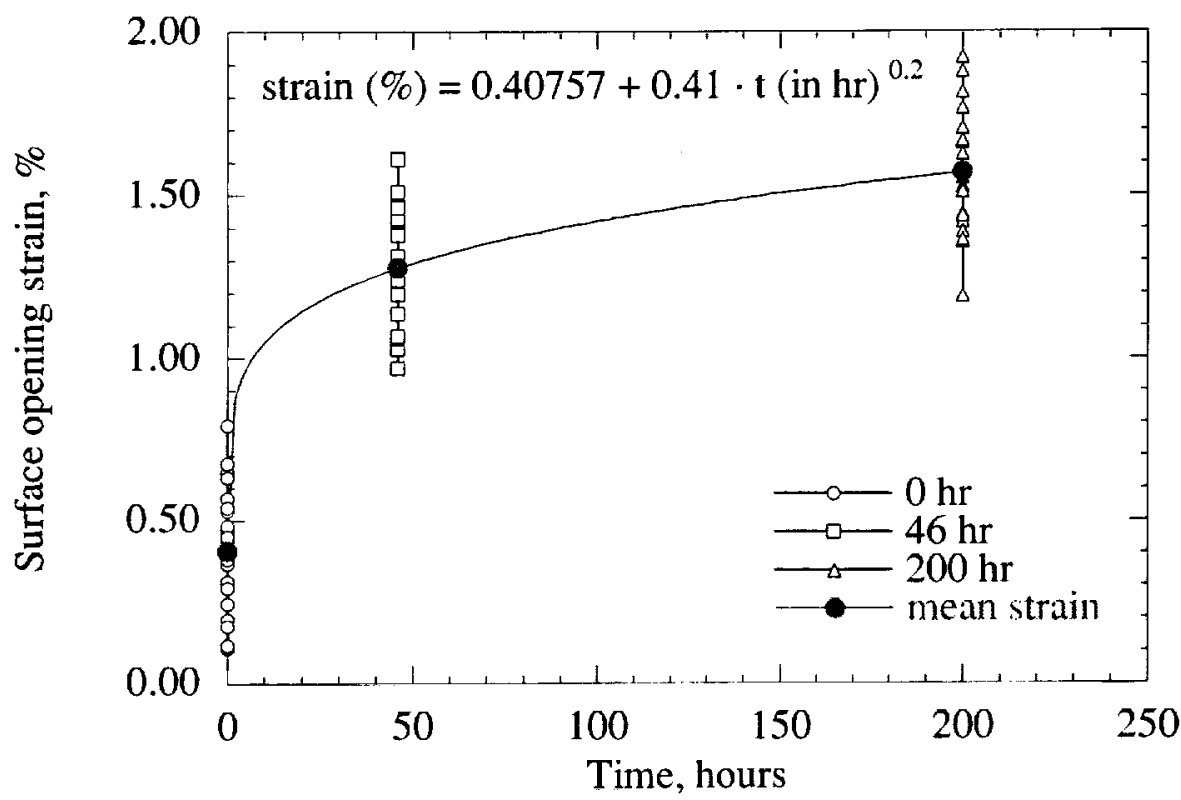

Fig. 7 The coating surface sintering strains derived from the surface crack displacements for $0.13 \mathrm{~mm}$ thick grooved EB-PVD coating specimens as a function of testing time. 


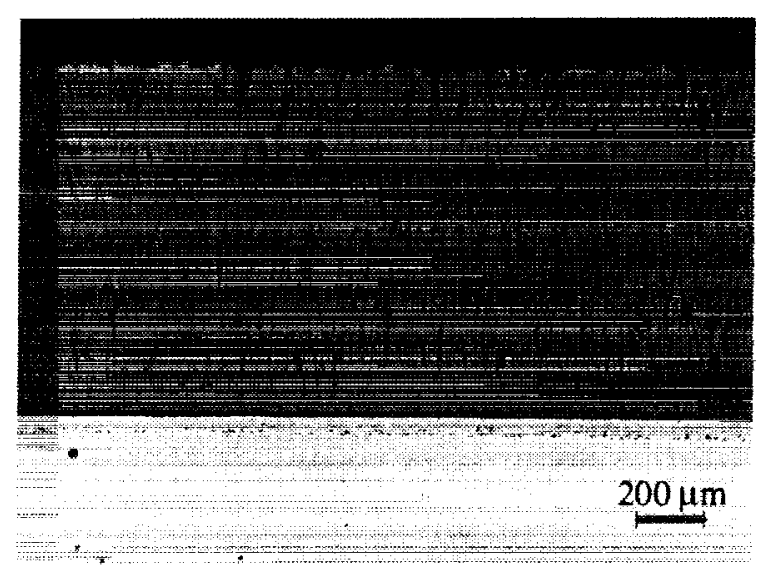

(a)

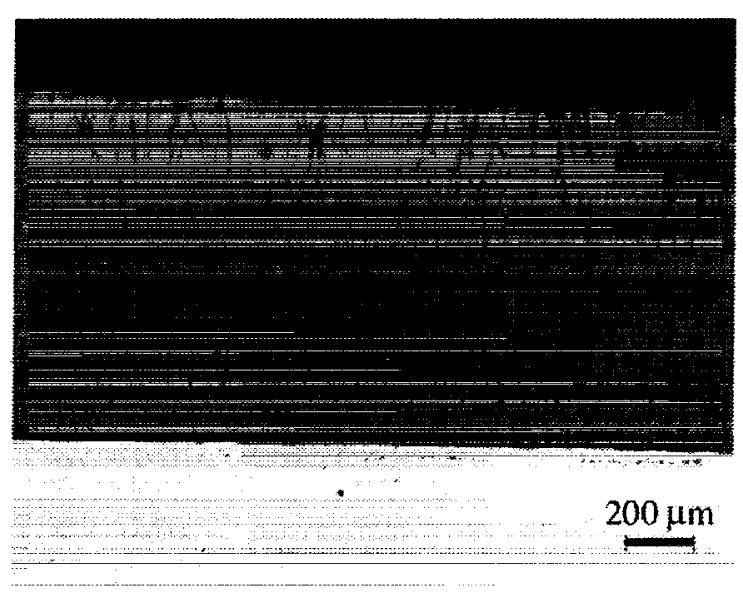

(b)

Fig. 8 Micrographs of cross-sections of the $1.0 \mathrm{~mm}$ thick EB-PVD coating showing significant coating sintering after the laser testing. (a) As processed; (b) after 60 hour, $1350^{\circ} \mathrm{C}$ surface temperature laser heat flux testing.

For the EB-PVD coatings, intra-columnar micro-pores also exist after the deposition process. With the laser high heat flux exposure, the intra-columnar micropores can be significantly sintered, and thus the intra-columnar porosity can be reduced. Figure 9 shows micrographs of the sintered intra-columnar micro-pores, and feather-like flakes. The long-term thermal conductivity increase observed from the laser conductivity tests are attributed to the sintering of both the inter-columnar and intra-columnar microporosity. 


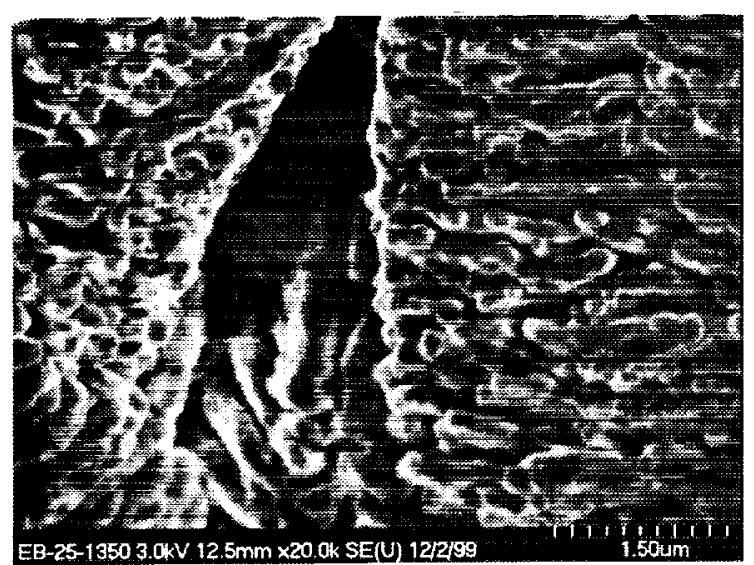

(a)

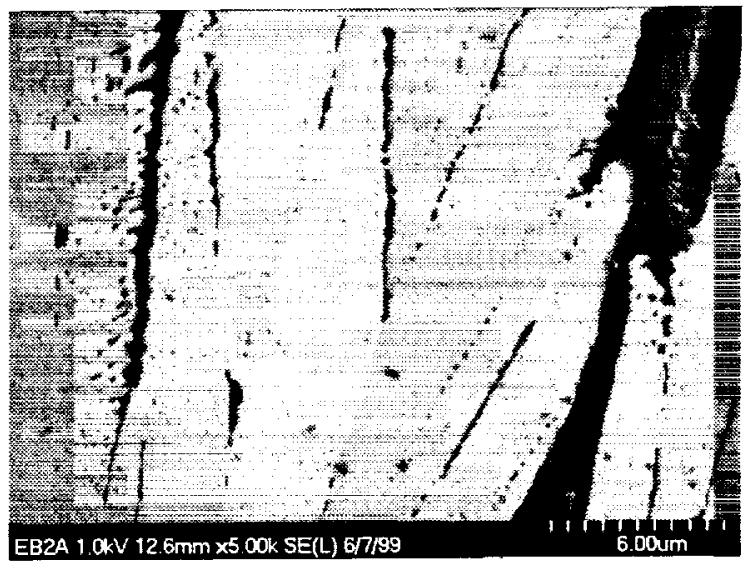

(b)

Fig. 9 Micrographs of the intra-columnar pore structures in EB-PVD coatings. (a)As processed columnar structure showing micro-pores and surrounding feather-like flakes; (b) Sintered intra-columnar micro-pores and feather-like flakes.

\section{Failure Modes of EB-PVD Coatings}

Figures 10 and 11 show typical coating cracking and failure mechanisms of the $1.3 \mathrm{~mm}$ thick, grooved and non-grooved EB-PVD coatings after $2 \mathrm{hr}$ cyclic high heat flux testing in the laser.

For the grooved EB-PVD coating, square-type surface cracks are generally observed. By comparing Figures 10 (a) and (b), it can be easily seen that the regularshaped surface-cracking pattern is closely related to the bond coat grooving pattern. During the cyclic testing, the wedge-shape vertical cracks quickly formed and initiated the delamination cracks in the coating, as shown in Figures 10 (c) and (d). The coating delamination cracks continued to propagate under the laser cyclic loading, but they are usually confined to within the coating segments between the vertical cracks. This is because the complex stress fields associated with the grooved rough interface can arrest the delamination cracks. The large variations of the measured thermal conductivity for the grooved EB-PVD coating can also be explained by the large amount of progressive micro-cracking and the sintering of coating segments during the laser testing. 
For the non-grooved EB-PVD coating, the distributions of the surface cracks are usually irregular, as shown in Figure 11 (a). Unlike the grooved coating, the non-grooved coating has initiated fewer delamination cracks probably due to fewer surface cracks. However, the delamination cracks have propagated to larger sizes after the laser testing because of the flat interface. A coating delamination crack is shown in Figure 11 (b). Delamination crack propagation has been demonstrated in the thermal conductivity test, as indicated by Figure 12. As mentioned earlier, this EB-PVD coating was previously laser cyclic tested where it sintered until the conductivity reached the approximate value of $1.65 \mathrm{~W} / \mathrm{m}-\mathrm{K}$ (relative to an assumed initial conductivity value of $1.5 \mathrm{~W} / \mathrm{m}-\mathrm{K}$ ). A delamination crack was believed to have initiated because a sudden large decrease in coating conductivity was noticed during the testing. The specimen was further tested in the laser heat flux test. From Figure 12, it can be seen that soon after applying the laser thermal exposure, the coating showed a high conductivity close to that of an intact coating. This is because the coating was still in relatively good contact with the substrate at the early stage of heating. Under continuing laser exposure, the coating became increasingly buckled and thus showed a lower steady-state conductivity value (of about $1.45 \mathrm{~W} / \mathrm{m}-\mathrm{K})$. The initial and steady-state conductivity measured became lower and lower with subsequent laser cyclic testing, suggesting the continuing propagation of the delamination crack. 


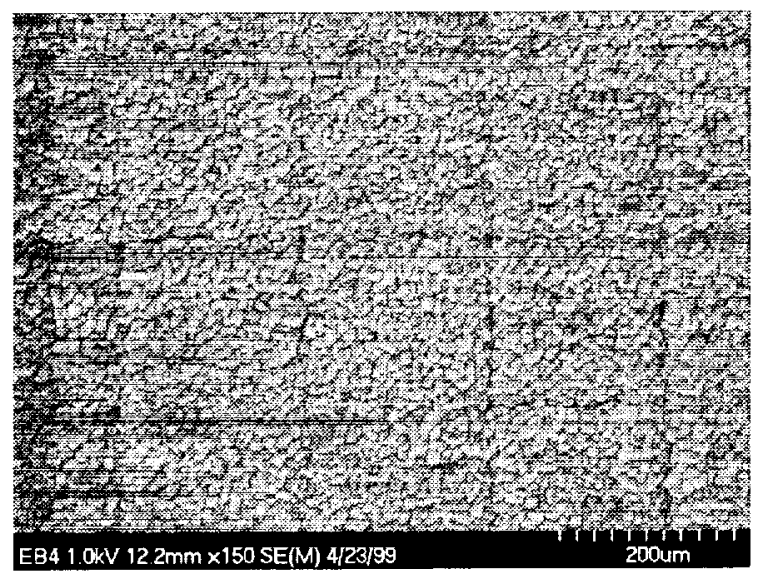

(a)

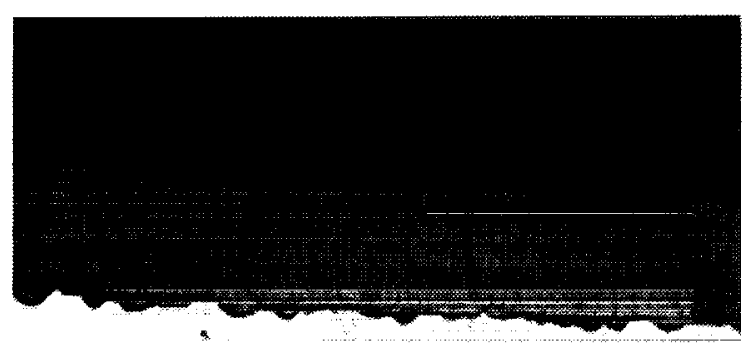

$100 \mu \mathrm{m}$

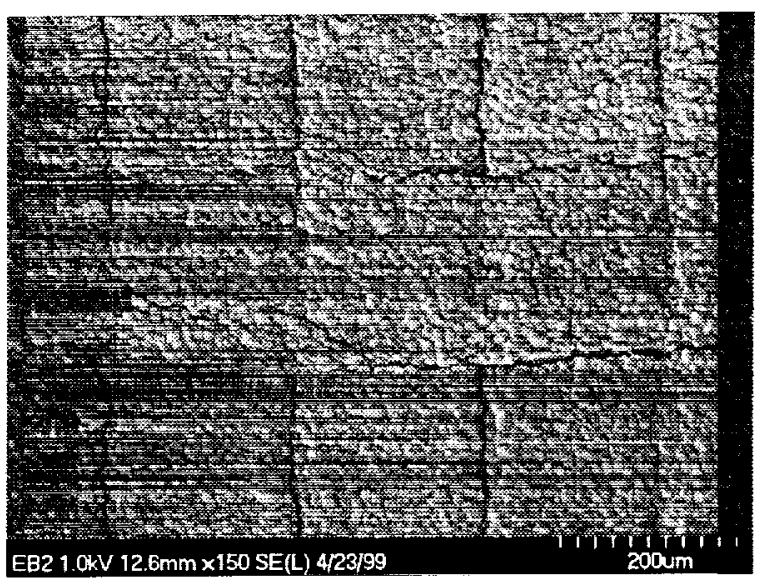

(b)

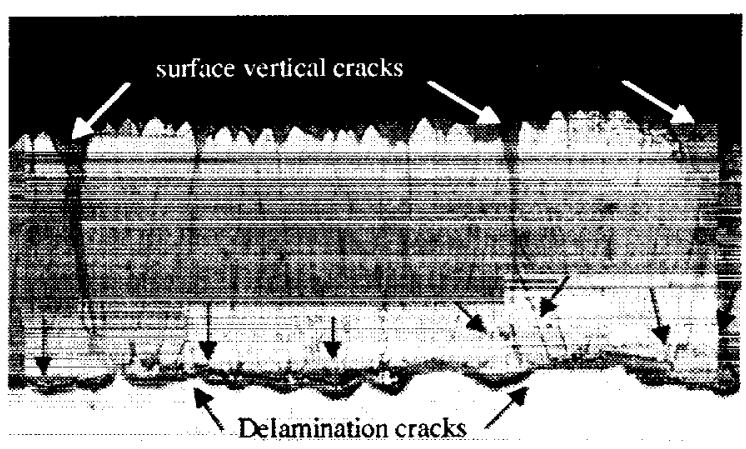

$50 \mu \mathrm{m}$

(c)

(d)

Fig. 10 Surface cracking patterns and delamination cracks after $200 \mathrm{hr}, 2 \mathrm{hr}$ cyclic laser high heat flux testing. (a) As-processed coating surface morphology showing the coating groove imprints; (b) Surface vertical cracking patterns after the 200 hr laser cyclic testing; (c) and (d) Micrographs of the coating cross-sections showing the wedge-shape coating vertical through-thickness cracks and the delamination cracks. 


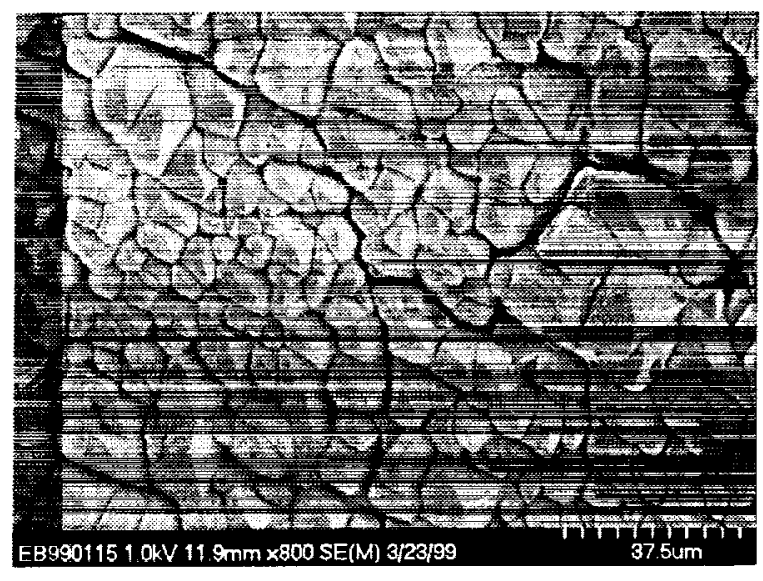

(a)

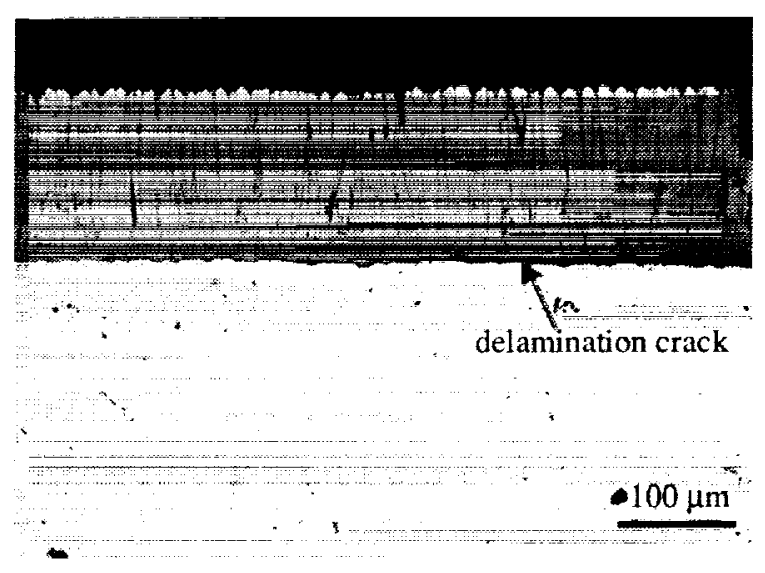

(b)

Fig. 11 Surface cracking and coating delamination observed in non-grooved EB-PVD coatings after the laser $40 \mathrm{hr}, 2 \mathrm{hr}$ cyclic testing. (a) The typical surface cracking pattern. (b) A large delamination crack that is associated with the coating surface through-thickness vertical crack.

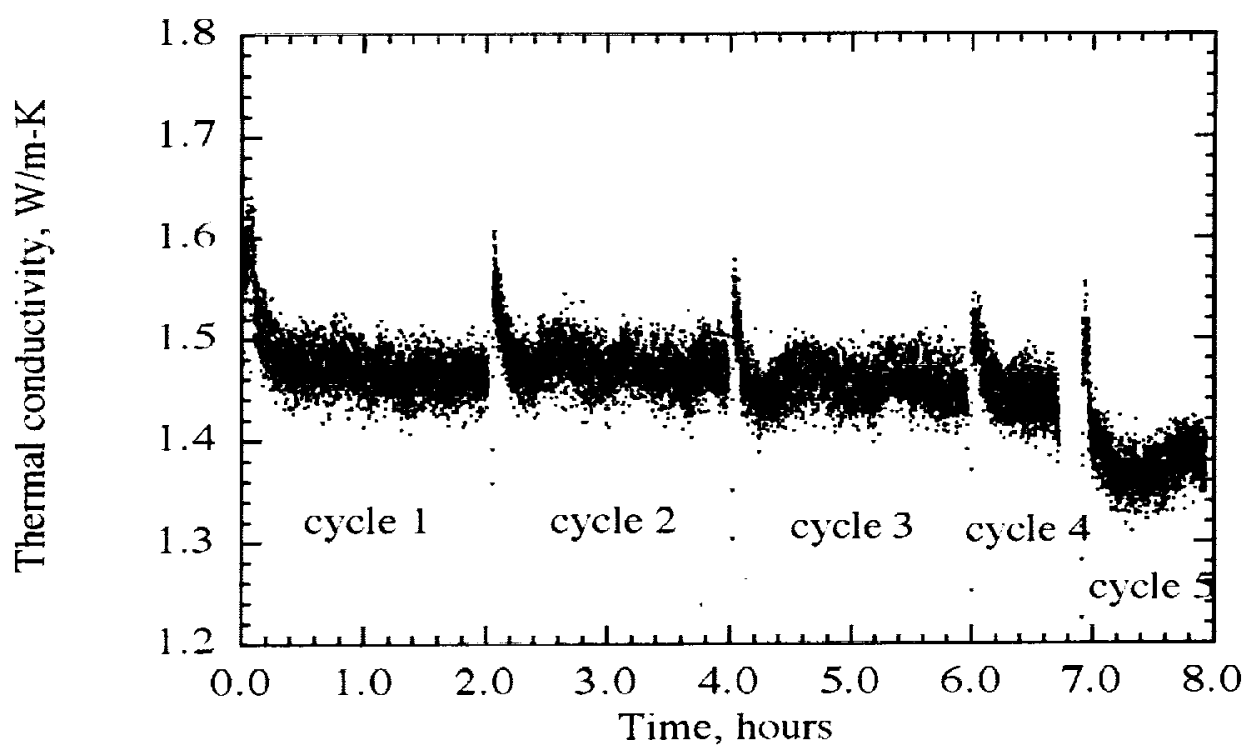

Fig. 12 Thermal conductivity response of a $0.13 \mathrm{~mm}$ thick, non-grooved EB-PVD coating near failure. Under the continuing exposure to the laser thermal load, the coating showed lower and lower initial and steady-state conductivity values, suggesting the continued propagation of the delamination crack. 


\section{CONCLUSIONS}

The thermal conductivity of electron beam-physical vapor deposited (EB-PVD) $\mathrm{ZrO}_{2}-8 \mathrm{wt} \% \mathrm{Y}_{2} \mathrm{O}_{3}$ thermal barrier coatings has been determined by a steady-state heat flux laser technique. The thermal conductivity increase of the EB-PVD ceramic coatings under high heat flux testing has been attributed to the sintering of both the inter-columnar and intra-columnar microporosity in EB-PVD coating systems. The coating microdelaminations can reduce the measured conductivity values, and have resulted in observed coating conductivity fluctuations during the laser thermal cyclic testing. The laser thermal conductivity tests have demonstrated the ability to investigate the coating delamination crack propagation, and provided insights into the coating failure mechanisms of the grooved and non-grooved EB-PVD coatings. The test technique provides a viable means for obtaining coating thermal conductivity data for use in design, development, and life prediction for engine applications.

\section{REFERENCE}

[1] H. E. Eaton, J. R. Linsey, and R. B. Dinwiddie, "The Effect of Thermal Aging on the Thermal Conductivity of Plasma Sprayed Fully Stabilized Zirconia," in Thermal Conductivity, vol. 22, T. W. Tong, Ed.: Technomic Publishing Co., Inc., Lancaster, Pennsylvania, 1994, pp. 289-300.

[2] R. B. Dinwiddie, S. C. Beecher, W. D. Porter, and B. A. Nagaraj, "The Effect of Thermal Aging on the Thermal Conductivity of Plasma-sprayed and EB-PVD Thermal Barrier Coatings," presented at The International Gas Turbine and Aeroengine Congress and Exhibition, Birmingham, UK, ASME Paper 96-GT$282,1996$.

[3] H. E. Eaton and R. C. Novak, "Sintering Studies of Plasma-Sprayed Zirconia," Surface and Coatings Technology, vol. 32, pp. 227-236, 1987. 
[4] D. Zhu and R. A. Miller, "Sintering and Creep Behavior of Plasma-Sprayed Zirconia and Hafnia-Based Thermal Barrier Coatings," Surface and Coatings Technology, vol. 108-109, pp. 114-120, 1998.

[5] D. Zhu and R. A. Miller, "Thermal Conductivity and Elastic Modulus Evolution of Thermal Barrier Coatings Under High Heat Flux Conditions," NASA Glenn Research Center, Cleveland, Ohio, NASA TM-209069, 1999.

[6] D. Zhu and R. A. Miller, "Thermal Conductivity Change Kinetics of Ceramic Thermal Barrier Coatings Determined by the Steady-State Laser Heat Flux Technique," NASA Glenn Research Center, Cleveland, Ohio, Research and Technology 1999.

[7] D. Zhu and R. A. Miller, "Thermophysical and Thermomechanical Properties of Thermal Barrier Coating Systems," Ceram. Eng. Sci. Proc., vol. 21, in press, 2000.

[8] R. A. Miller and D. Zhu, "Laser Rig Testing of Thermal Barrier Coatings," presented at International Conference on Metallurgical Coatings and Thin Films, San Diego, CA, 2000.

[9] D. Zhu and R. A. Miller, "Determination of Creep Behavior of Thermal Barrier Coatings under Laser Imposed High Thermal and Stress Gradient Conditions," Journal of Materials Research, vol. 14, pp. 146-161, 1999. 


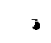

.

. 
Davis Highway. Suite 1204, Arlington, VA 22202-4302, and to the Office of Management and Budget, Paperwork Reduction Project (0704-0188), Washington, DC 20503.

\begin{tabular}{|l|c|c} 
1. AGENCY USE ONLY (Leave blank) & $\begin{array}{c}\text { 2. REPORT DATE } \\
\text { July } 2000\end{array}$ & $\begin{array}{r}\text { 3. REPORT TYPE AND DATES COVERED } \\
\text { Technical Memorandum }\end{array}$
\end{tabular}

4. TITLE AND SUBTITLE

Thermal Conductivity of EB-PVD Thermal Barrier Coatings Evaluated by a Steady-State Laser Heat Flux Technique

6. AUTHOR(S)

Dongming Zhu, Robert A. Miller, Ben A. Nagaraj, and Robert W. Bruce

\section{PERFORMING ORGANIZATION NAME(S) AND ADDRESS(ES)}

National Aeronautics and Space Administration

John H. Glenn Research Center at Lewis Field

Cleveland, Ohio 44135-3191

9. SPONSORINGMONITORING AGENCY NAME(S) AND ADDRESS(ES)

National Aeronautics and Space Administration

Washington, DC 20546-0001
WU-714-04-20-00

NCC $3-617$

8. PERFORMING ORGANIZATION REPORT NUMBER

E-12357
10. SPONSORING/MONITORING AGENCY REPORT NUMBER

NASA TM-2000-210238

11. SUPPLEMENTARY NOTES

Prepared for the International Conference on Metallurgical Coatings and Thin Films sponsored by the American Vacuum Society, San Diego, California, April 10-14, 2000. Dongming Zhu. Ohio Aerospace Institute, 22800 Cedar Point Road, Brook Park, Ohio 44142; Robert A. Miller, NASA Glenn Research Center; Ben A. Nagaraj and Robert W. Bruce, General Electric Aircraft Engines, One Neumann Way, MD B-5, Cincinnati, Ohio 45215-1988. (Work funded by NASA Cooperative Agreement NCC3-61 7.) Responsible person, Dongming Zhu, organization code 5160, (216) 433-5422.

12a. DISTRIBUTION/AVAILABILITY STATEMENT 12b. DISTRIBUTION CODE

Unclassified - Unlimited

Subject Categories: 24 and 25

Distribution: Nonstandard

This publication is available from the NASA Center for AeroSpace Information, (301) 621-0390.

13. ABSTRACT (Maximum 200 words)

The thermal conductivity of electron beam-physical vapor deposited (EB-PVD) $\mathrm{ZrO}_{2}-8 \mathrm{wt} \% \mathrm{Y}_{2} \mathrm{O}_{3}$ thermal barrier coatings was determined by a steady-state heat flux laser technique. Thermal conductivity change kinetics of the EB-PVD ceramic coatings were also obtained in real time, at high temperatures, under the laser high heat flux, longterm test conditions. The thermal conductivity increase due to micro-pore sintering and the decrease due to coating micro-delaminations in the EB-PVD coatings were evaluated for grooved and non-grooved EB-PVD coating systems under isothermal and thermal cycling conditions. The coating failure modes under the high heat flux test conditions were also investigated. The test technique provides a viable means for obtaining coating thermal conductivity data for use in design, development, and life prediction for engine applications.

\section{SUBJECT TERMS}

Thermal barrier coatings; Life predictions; Thermal conductivity;

Thermal gradient testing; Coating delamination

\begin{tabular}{|c|c|}
\hline 17. SECURITY CLASSIFICATION & 18. SECURITY CLASSIFICATION \\
OF REPORT & OF THIS PAGE \\
Unclassified & Unclassified
\end{tabular}

19. SECUAITY CLASSIFICATION OF ABSTRACT Unclassified 